\title{
Interobserver variation in the diagnosis and grading of dyskaryosis in cervical smears: Specialist cytopathologists compared with non-specialists
}

Department of Histopathology, St Richard's Hospital, Chichester

J P O'Sullivan

Department of Pathology, University of Wales College of Medicine, Cardiff S M Ismail

Department of Histopathology, Conquest Hospital, St Leonard's-on-Sea, East Sussex W S F Barnes

Department of Cytopathology, The Royal Free Hospital, London

A R S Deery

Department of Histopathology, Whiston Hospital, Prescot, Merseyside E Gradwell

Department of Histopathology, County Hospital, Lincoln

J A Harvey

Department of Cytopathology, Charing Cross Hospital, London O A N Husain

Department of Cytopathology, University College London Medical School

G Kocjan

Department of Cytopathology, Royal Surrey County Hospital, Guildford G McKee

Department of Cytopathology, Llandough Hospital, Penarth, South Glamorgan $R$ Olafsdottir

Department of Histopathology, St Peter's Hospital, Chertsey, Surrey

N A Ratcliffe

Department of

Medical Computing and Statistics University of Wales College of Medicine, Cardiff

R G Newcombe

Correspondence to: Dr J P O'Sullivan, Department of Histopathology, St Richard's Hospital, Spitalfield Lane, PO19 4SE.

Accepted for publication 14 December 1993

J P O'Sullivan, S M Ismail, W S F Barnes, A R S Deery, E Gradwell, J A Harvey,
O A N Husain, G Kocjan, G McKee, R Olafsdottir, N A Ratcliffe, R G Newcombe

\section{Abstract}

Aims-To compare the assessment of dyskaryosis in cervical smears made by specialist consultant cytopathologists and consultant general histopathologists.

Methods-One hundred and ten cervical smears were circulated to 10 observers from five district general hospital histopathology departments and five major departments of cytopathology. Their responses were analysed by five consultant general histopathologists and five consultant specialist cytopathologists. In 54 of the 110 cases, the histology of a corresponding cervical biopsy specimen was compared with the smear assessments. Results-Specialist cytopathologists were more consistent than non-specialists when diagnosing and grading dyskaryosis. They chose the higher grades of dyskaryosis more frequently than the non-specialists.

The cytopathologists recommended referral for colposcopy more frequently, but if they asked for a repeat smear, they wanted it done within three months more frequently than the histopathologists. The specialists were more frequently in agreement with the biopsy grade of intra-epithelial neoplasia than the nonspecialists, whose smear diagnoses tended to underestimate the severity of the histopathological abnormality.

Conclusions-This study has shown major differences between specialist and non-specialist cytopathologists in the diagnosis and grading of cervical smears and in the recommended management of patients with abnormal smears. These differences may result in uneven clinical management of women with smear abnormalities. It is therefore important to explore possible strategies for standardising the reporting of cervical smears, such as centralisation of screening services, accreditation in cytopathology for non-specialist consultants, and the value of participation in external quality assessment schemes.

$(\mathfrak{F}$ Clin Pathol 1994;47:515-518)

The increase in the number of cervical smears performed in England and Wales as a result of the cervical screening programme has meant that more consultant pathologists who can undertake cytopathology are needed. The Royal College of Pathologists ${ }^{1}$ has expressed the view that additional consultant posts are necessary, but felt that the creation of whole time posts in cytopathology was not the appropriate solution. It was proposed, instead, that newly created consultant posts should be half time cytopathology and half time histopathology. Noticeably, most advertisements for consultant histopathology posts in district general hospitals now specify that the successful candidate must take part in the cytopathology service.

In university departments, however, and in some of the larger district general hospitals there is a separate subdepartment of cytopathology run by one or more consultant cytopathologists. These departments usually have a much greater cytopathology workload than the average district general hospital laboratory, although this may be due to larger numbers of non-gynaecological specimens rather than cervical smears. They may also function as training centres for pathologists and cytoscreeners.

Thus a cervical smear deemed abnormal by cytoscreeners will be reported either by a specialist consultant cytopathologist or a general consultant histopathologist who undertakes not only cytopathology but also surgical pathology and postmortem examinations. We have designed a study which compares, for the first time, as far as we are aware, cervical smear reporting by these two groups of consultant pathologists.

\section{Methods}

One hundred and ten cervical smears were circulated, in batches of 10 , to the panel of observers. The smears had been received by one of the participants (JPO'S), after having been screened at both a primary and at a more senior level before being passed on as requiring a consultant opinion. Because the slides included the output of a number of busy colposcopy clinics, there were more abnormal smears than would have been expected from a routine screening population.

The panel of observers comprised five consultant histopathologists and five specialist consultant cytopathologists. The consultant histopathologists worked in district general hospitals and carried out duties in surgical pathology and necropsy work as well as cytopathology. The cytopathologists' duties were largely or completely confined to 
Table 1 Variation among cytopathologists for 110 smears classified as dyskaryosis

\begin{tabular}{lcccccrrr}
\hline & Inadequate & Negative & B/line & Mild & Moderate & Severe & ? Invasive & Total \\
\hline Inadequate & $\mathbf{1 4}$ & 24 & 10 & 7 & 3 & 4 & 2 & 64 \\
Negative & 24 & 84 & 40 & 6 & 6 & 20 & 12 & 192 \\
B/line & 10 & 40 & 76 & 69 & 32 & 4 & 1 & 232 \\
Mild & 7 & 6 & 69 & 236 & 155 & 20 & 3 & 496 \\
Moderate & 3 & 6 & 32 & 155 & 230 & 91 & 7 & 524 \\
Severe & 4 & 20 & 4 & 20 & 91 & 290 & 67 & 496 \\
? Invasive & 2 & 12 & 1 & 3 & 7 & 67 & 104 & 196 \\
Total & 64 & 192 & 232 & 496 & 524 & 496 & 196 & 2200 \\
\hline
\end{tabular}

Table 2 Variation among histopathologists for 110 smears classified as dyskaryosis

\begin{tabular}{lcccccccr}
\hline & Inadequate & Negative & Blline & Mild & Moderate & Severe & ? Invasive & Total \\
\hline Inadequate & 20 & 37 & 7 & 10 & 3 & 10 & 1 & 88 \\
Negative & 37 & 84 & 42 & 61 & 16 & 41 & 3 & 284 \\
B/line & 7 & 42 & 22 & 85 & 20 & 20 & 4 & 200 \\
Mild & 10 & 61 & 85 & 430 & 137 & 84 & 17 & 824 \\
Moderate & 3 & 16 & 20 & 137 & 60 & 52 & 16 & 304 \\
Severe & 10 & 41 & 20 & 84 & 52 & 168 & 29 & 404 \\
? Invasive & 1 & 3 & 4 & 17 & 16 & 29 & 26 & 96 \\
Total & 88 & 284 & 200 & 824 & 304 & 404 & 96 & 2200 \\
\hline
\end{tabular}

cytopathology. The participants were asked to decide on the presence and grade of dyskaryosis and to specify their recommendations for further management. No clinical details were supplied.

In 54 of the 110 cases a cervical biopsy specimen had been taken at the same time as the cervical smear. These biopsy specimens were examined, without knowledge of the cervical smear findings, by an independent consultant histopathologist with a special interest in gynaecological pathology (SMI). They were graded as showing normal squamous epithelium, hyperplastic squamous epithelium, cervical intraepithelial neoplasia (CIN) grades I, II, III, or invasive carcinoma. The biopsy findings were compared with the observers' opinions on the corresponding smears.

\section{DATA ANALYSIS}

The degree of agreement between observers was expressed by $\kappa$ type statistics. The simple $\kappa$ statistic, introduced by Cohen, ${ }^{2}$ takes account of the fact that part of an observed agreement between observers is due to chance. Kappa is the observed agreement, corrected for chance agreement, divided by the maximum possible agreement, also corrected for chance agreement. That is to say, it expresses numerically the excess of the observed agreement over the chance agreement. For the classifications where there were more than two choices open to the observer, such as the degree of dyskaryosis, the weighted $\kappa^{3}$ was calculated, to allow for the fact that some disagreements are more serious than others, and to give greater numerical weight to such disagreements. A weighted $\kappa$ value of more than 0.5 was arbitrarily taken as representing reasonable interobserver agreement.

To compare the behaviour of the groups in their assessment of cervical smears and in their recommendations for management, the decisions of each group (five individuals) for each smear (110 smears) - 550 observations, for each of a number of parameters-were assembled. To analyse whether the observed differences were consistent across individual smears, each smear was given two scores: what proportion of the five histopathologists regarded it as showing a particular feature; and what proportion of the five cytopathologists did so. A paired $t$ test and corresponding $95 \%$ confidence interval were used to assess the degree to which one group of observers reported the feature more than the other group. Estimated mean differences may differ slightly from the difference between the two proportions when some of the 550 observations are classed as inadequate and therefore excluded.

For the 54 smears for which there was an accompanying biopsy specimen, tables comparing the biopsy histology and the smear assessments for dyskaryosis were constructed, excluding readings classed as inadequate. Each patient was characterised by the proportion of cytopathologists who assigned a more severe grade than the biopsy specimen minus the proportion who assigned a less severe grade, representing the tendency of cytopathologists to over- rather than undercall in that case, and a corresponding difference of proportions for the histopathologists.

\section{Results}

To assess the degree of agreement among the specialist cytopathologists, a symmetrical agreement matrix (table 1) was formed in which each observation from each cytopathologist was compared with the corresponding observations made by the other four observers:

yielding 5 (observers) $\times 4$ (comparisons) $\times 110$ (smears) $=2200$ paired comparisons in all.

A similar table (table 2) was constructed for the general histopathologists. Weighted $\kappa$ statistics derived from these tables show that specialist cytopathologists achieved considerably greater agreement than the non-specialists who showed little more agreement than would be expected by chance (table 3 ).

Similar matrices were constructed for management recommendations and are available from J P O'Sullivan. These also show a much greater degree of consistency among specialist

Table 3 Internal consistency of the groups

\begin{tabular}{|c|c|c|c|c|c|c|}
\hline & \multicolumn{3}{|c|}{ Cytopathologists } & \multicolumn{3}{|c|}{ Histopathologists } \\
\hline & \multicolumn{3}{|c|}{ Proportion agreement } & \multicolumn{3}{|c|}{ Proportion agreement } \\
\hline & Observed & Expected & Weighted $\kappa$ & Observed & Expected & Weighted $\kappa$ \\
\hline $\begin{array}{l}\text { Grade of dyskaryosis } \\
\text { Management }\end{array}$ & $\begin{array}{l}0.95 \\
0.96\end{array}$ & $\begin{array}{l}0.85 \\
0.92\end{array}$ & $\begin{array}{l}0.64 \\
0.54\end{array}$ & $\begin{array}{l}0.91 \\
0.91\end{array}$ & $\begin{array}{l}0.86 \\
0.90\end{array}$ & $\begin{array}{l}0.36 \\
0.12\end{array}$ \\
\hline
\end{tabular}


Table 4 Degree of dyskaryosis recorded by cytopathologists and histopathologists

\begin{tabular}{|c|c|c|c|c|c|c|}
\hline & $\begin{array}{l}\text { Cytopathologists } \\
\text { (534 readings) }\end{array}$ & $\begin{array}{l}\text { Histopathologists } \\
\text { (528 readings) }\end{array}$ & Difference & $\begin{array}{l}95 \% \text { confidence } \\
\text { interval }\end{array}$ & $t$ test & p value \\
\hline $\begin{array}{l}\text { Normal } \\
\text { Borderline } \\
\text { Mild } \\
\text { Moderate } \\
\text { Severe } \\
\text { ? Invasive } \\
\text { (Severe + ? invasive) }\end{array}$ & $\begin{array}{c}48(9 \cdot 0 \%) \\
58(10 \cdot 9 \%) \\
124(23 \cdot 2 \%) \\
131(24 \cdot 5 \%) \\
124(23 \cdot 2 \%) \\
49(9 \cdot 2 \%) \\
173(32 \cdot 4 \%)\end{array}$ & $\begin{array}{c}71(13 \cdot 4 \%) \\
50(9 \cdot 5 \%) \\
206(39 \cdot 0 \%) \\
76(14 \cdot 4 \%) \\
101(19 \cdot 1 \%) \\
24(4 \cdot 5 \%) \\
125(23 \cdot 7 \%)\end{array}$ & $\begin{array}{l}-4 \cdot 9 \% \\
+1 \cdot 5 \% \\
-15 \cdot 1 \% \\
+10 \cdot 0 \% \\
+3 \cdot 9 \% \\
+4 \cdot 6 \% \\
+8 \cdot 5 \%\end{array}$ & $\begin{array}{l}-7 \cdot 5 \% \text { to }+2 \cdot 3 \% \\
-1 \cdot 7 \% \text { to }+4 \cdot 8 \% \\
-20 \cdot 1 \% \text { to }-10 \cdot 1 \% \\
+4 \cdot 8 \% \text { to }+15 \cdot 1 \% \\
-1 \cdot 2 \% \text { to }+9 \cdot 0 \% \\
+1.5 \% \text { to }+7 \cdot 8 \% \\
+3.9 \% \text { to }+13 \cdot 2 \%\end{array}$ & $\begin{array}{l}-3.80 \\
+0.93 \\
+5.95 \\
+3.85 \\
+1.51 \\
+2.92 \\
+3.65\end{array}$ & $\begin{array}{l}0.0002 \\
0.36 \\
<0.0001 \\
0.0002 \\
0.13 \\
0.0042 \\
0.0004\end{array}$ \\
\hline
\end{tabular}

Table 5 Management recommendations made by cytopathologists and histopathologists

\begin{tabular}{|c|c|c|c|c|c|c|}
\hline & $\begin{array}{l}\text { Cytopathologists } \\
\text { (550 readings) }\end{array}$ & $\begin{array}{l}\text { Histopathologists } \\
\text { (550 readings) }\end{array}$ & Difference & $\begin{array}{l}95 \% \text { confidence } \\
\text { interval }\end{array}$ & $t$ test & $p$ value \\
\hline $\begin{array}{l}\text { Refer colposcopy or } \\
\text { other investigation } \\
\text { Early recall }\end{array}$ & $\begin{array}{l}288(52 \cdot 4 \%) \\
112(20 \cdot 4 \%)\end{array}$ & $\begin{array}{c}246(44 \cdot 7 \%) \\
47(8 \cdot 5 \%)\end{array}$ & $\begin{array}{l}+7 \cdot 6 \% \\
+11 \cdot 8 \%\end{array}$ & $\begin{array}{l}+3 \cdot 0 \% \text { to }+12 \cdot 3 \% \\
+7 \cdot 1 \% \text { to }+16 \cdot 6 \%\end{array}$ & $\begin{array}{l}+3 \cdot 25 \\
+4.93\end{array}$ & $\begin{array}{r}0.0016 \\
<0.0001\end{array}$ \\
\hline
\end{tabular}

Table 6 Comparison with the biopsy findings

\begin{tabular}{lccc}
\hline & $\begin{array}{l}\text { Cytopathologists } \\
(266 \text { readings) }\end{array}$ & $\begin{array}{l}\text { Histopathologists } \\
(267 \text { readings })\end{array}$ & Difference \\
\hline Above biopsy diagnosis & $82(30 \cdot 8 \%)$ & $61(22 \cdot 8 \%)$ & \\
Complete agreement & $107(40 \cdot 2 \%)$ & $87(32 \cdot 6 \%)$ & \\
Below biopsy diagnosis & $77(28 \cdot 9 \%)$ & $119(44 \cdot 6 \%)$ & $+23 \cdot 9 \%$ \\
Tendency to over- rather than undercall & $+2 \cdot 2 \%$ & $-21 \cdot 7 \%$ & $+13 \cdot 5 \%$ to $+34 \cdot 2 \%$ \\
$95 \%$ confidence interval & $-15 \cdot 1 \%$ to $+19 \cdot 5 \%$ & $-37 \cdot 5 \%$ to $-5 \cdot 9 \%$ & +61 \\
$t$ test & $+0 \cdot 25$ & $-2 \cdot 75$ & $0 \cdot 0001$ \\
p value & 0.80 & 0.0081 & \\
\hline
\end{tabular}

cytopathologists than non-specialists (table 3).

Table 4 examines the frequency with which the two groups of pathologists assigned the smears into the six diagnostic categories (normal, borderline, mild, moderate, severe and invasive). The non-specialists diagnosed normality and mild dyskaryosis significantly more frequently than did the specialist cytopathologists. The latter, however, had a significantly greater index of suspicion for invasive carcinoma.

When the management recommendations of the two groups were compared (table 5), the cytopathologists suggested referral for colposcopy significantly more often than the histopathologists. They also requested a repeat smear within three months-that is, early recall-significantly more often than the histopathologists.

Table 6 examines the degree of agreement with the biopsy findings achieved by the two groups of observers. Although the 54 cervical biopsy specimens were of different types (12 colposcopic biopsies, 38 loop excisions, and four knife conisations) they were not subdivided for comparison purposes. The specialist cytopathologists agreed with the biopsy findings substantially more often than the nonspecialists. When they differed from the biopsy diagnosis the non-specialists underestimated the severity of the biopsy abnormality significantly more often than the specialists.

\section{Discussion}

Our results show that there were major differences in the interpretation of cervical smear abnormalities between the two groups of pathologists, which suggests that general histopathologists who practise cytopathology need further training in it. Specialist cytopathologists were more consistent among themselves than non-specialists when diagnosing dyskaryosis and more frequently agreed with the biopsy diagnosis. The nonspecialists diagnosed mild dyskaryosis in preference to the other diagnostic categories and frequently underestimated the severity of the biopsy diagnosis. In line with their tendency to diagnose higher grades of abnormality the specialists advised colposcopy, other gynaecological referral, and "repeat smear within three months" more often than the nonspecialists who were very inconsistent in their overall management recommendations. In terms both of internal consistency and concordance with the biopsy diagnosis, therefore, the non-specialist cytopathologists performed less well than the specialists.

The tendency of the non-specialists to diagnose mild dyskaryosis in preference to other diagnostic categories may well be a major cause of the disparity between mildly abnormal cervical cytology and histology noted by other investigators. ${ }^{45}$ In contrast, the specialist cytopathologists showed a preference for the higher grades of abnormality and, in particular, raised the possibility of invasive carcinoma far more frequently than did the histopathologists. The latter finding may simply reflect the underlying philosophy of screening which aims to detect smear abnormalities and to have them treated without delay; a suspicion of invasiveness in this context is likely to expedite an appointment for colposcopic evaluation and biopsy of the cervix. The non-specialist cytopathologists, who are primarily histopathologists, would be biased against raising a suspicion of invasive malignancy because such a diagnosis in biopsy material is frequently a precursor to major surgery. 
This study may be criticised for attempting to correlate biopsy histology with smear abnormalities. We would maintain that these two different tests, although dependent on different variables, should reflect the nature of the underlying lesion and thus show a good correlation. That the biopsy interpretation was carried out by only one pathologist may be regarded as inconsistent with the philosophy of a study on interobserver variation. However, the observer in question not only had a special interest in cervical pathology but, having conducted two previous studies on observer variation in the reporting of cervical biopsy specimens, ${ }^{67}$ was aware of the problems of subjectivity in this area.

The British Society of Clinical Cytology has recognised that there is a widespread lack of uniformity in cervical smear reporting and has produced guidelines on grading dyskaryosis $^{8}$ as well as advice on management recommendations. ${ }^{9}$ These guidelines may in part be responsible for the consistency achieved by the specialist cytopathologists. However, the performance of the non-specialists, who report a substantial proportion, if not the majority, of abnormal cervical smears in the United Kingdom, suggests that standardisation of cervical smear reporting is far from optimal.

Centralisation of cervical smear reporting in specialist laboratories is the single course of action which might simultaneously improve the quality of reporting and its consistency. However, this option would be expensive and would require major reorganisation of existing services. Furthermore, it would be impracticable because it would result in a sudden demand for specialist consultants in cyto- pathology which would be out of keeping with the number of trainees in the specialty. The second possible option, favoured by six of the 10 panel members, that cytopathology should be carried out by specialist cytopathologists appointed to district general hospitals, would be unworkable for similar reasons. In the current economic climate, it might be more practicable and less disruptive to introduce an accreditation scheme in cytopathology for non-specialist consultants which could be combined with the regional external quality assessment schemes currently in operation.

1 Burston J, Hudson E, Williams ED. Consultant histopathologists with responsibility for cytopathology. Bull Roy Coll Pathol 1988;61:14-18.

2 Cohen J. A coefficient of agreement for nominal scales. Educational and Psychological Measurement. 1960;20: 37-46.

3 Cohen J. Weighted kappa: nominal scale agreement with provision for scaled disagreement or partial credit. Psychol Bull 1968;70:213-20.

4 Soutter WP, Wisdom S, Brough AK, Monaghan JM. Should patients with mild atypia in a cervical smear be referred for colposcopy? $\mathrm{Br} \mathcal{F}$ Obstet Gynaecol 1986; 93:70-4.

5 Campion MJ, McCance DJ, Cuzick J, Singer A. Progressive potential of mild cervical atypia. Prospective cytological, colposcopic and virological study. Lancet 1986;ii:237-40.

6 Ismail SM, Colclough AB, Dinnen JS, Eakins D, Evans $\mathrm{DMD}$, Gradwell $\mathrm{E}$, et al. Observer variation in histopathological diagnosis and grading of cervical intraepithelial neoplasia. $\mathrm{Br} \mathrm{Med} ₹$ 1989;298:707-10.

7 Ismail SM, Colclough AB, Dinnen JS, Eakins D, Evans DMD, Gradwell E, et al. Reporting cervical intraepithelial neoplasia $(\mathrm{CIN})$ : Intra- and interpathologist variation and factors associated with disagreement. Histopathology 1990;16:371-6.

8 Evans DMD, Hudson EA, Brown CL, Boddington MM, Hughes HE, MacKenzie EF, et al. Terminology in gynaecological cytopathology: report of the working party of the British Society for Clinical Cytology. 7 Clin Pathol 1986;39:933-44.

9 Evans DMD, Hudson EA, Brown CL, Boddington MM, Hughes HE, MacKenzie EFD. Management of women with abnormal cervical smears: supplement to terminology in gynaecological cytopathology. $f$ Clin Pathol ogy in gynaec 